\title{
Pelvic adhesion formation at second-look surgery after laparoscopic partial and total peritoneal excision for women with endometriosis
}

\author{
A. Oboh • A. K. Trehan
}

Received: 13 July 2006 / Accepted: 10 May 2007 / Published online: 11 July 2007

(C) Springer-Verlag 2007

\begin{abstract}
The purpose of this study was to determine the incidence of pelvic adhesion formation at second-look surgery after laparoscopic excision of the pelvic peritoneum for pelvic endometriosis. The setting was a district hospital in the UK with a specialised unit for laparoscopic surgical treatment of endometriosis; this was a retrospective study. We used data from the hospital computer database to identify patients who had undergone laparoscopic excision of pelvic endometriosis from April 1998 to March 2004. All subsequent admissions for surgery (laparoscopic or open) were reviewed for the presence of pelvic adhesions as documented in the records and collaborated with photographs from surgery. Forty-eight cases were identified from a cohort of 236 patients who initially had laparoscopic excision of pelvic peritoneum affected with endometriosis. Forty-six had laparoscopic surgery and two had open surgery. At second look surgery, 44 patients (91.7\%) had no de-novo pelvic adhesions in the areas where the initial excision was performed. Four patients $(8.3 \%)$ had filmy adhesions in the pelvis; these patients had other surgical procedures (two had LAVH) or on-going disease (one with recto-vaginal endometriosis nodule and the other with ovarian endometrioma at initial surgery). There were no dense or significant pelvic adhesions. Laparoscopic excision of the pelvic peritoneum as a treatment for pelvic peritoneal endometriosis is not associated with significant pelvic adhesion formation.
\end{abstract}

A. Oboh $(\bowtie)$

Department Obstetrics and Gynaecology,

Pontefract General Infirmary Friarwood lane Pontefract,

WF8 1PL Pontefract, UK

e-mail: alexanderoboh@hotmail.com

A. K. Trehan

Department Obs \& Gynae, Dewsbery District General,

Dewsbery, UK
Keywords Endometriosis · Laparoscopy · Peritoneum · Excision · Adhesion

\section{Introduction}

The role of surgery in the treatment for pelvic peritoneal endometriosis has been validated by several studies [1-7]. Surgical treatment by laparoscopic excision of pelvic peritoneal endometriosis is effective in relieving dysmenorrhoea, dyspareunia, chronic pelvic pain and dyschezia [2]. The Cochrane systematic review also agreed that surgical treatment has a beneficial effect on pelvic pain and infertility in women with mild to moderate endometriosis [3]. However this benefit has to be balanced with the risk of pelvic adhesion formation after surgery.

Adhesion formation is common and occurs after almost every abdominal surgery [8]. It is difficult to ascertain the true incidence of peritoneal adhesion formation after surgery because adhesions may vary from minimal asymptomatic scarring to dense adhesions and none of the scoring systems for adhesions has been validated [9]. The reported incidence of postoperative peritoneal adhesion formation after surgery has been reported to be as high as $60 \%-95 \%$ in patients at subsequent surgery $[9,10]$. Recent epidemiological data have demonstrated that one-third of patients who had open surgery were readmitted with adhesion-related complications within 10 years [11]. A subsequent analysis (SCAR-2) of women who had gynaecological operationlaparoscopy or laparotomy-also showed an increased risk of adhesion-related admission [12]. It also confirms that certain open surgical procedures (e.g., ovarian, tubal and adhesiolysis) have a higher risk of adhesion formation.

Although the majority of adhesions has no detrimental effect on women, a proportion suffers serious short- and 
Fig. 1 Excision of pelvic endometriosis does not cause pelvic adhesion
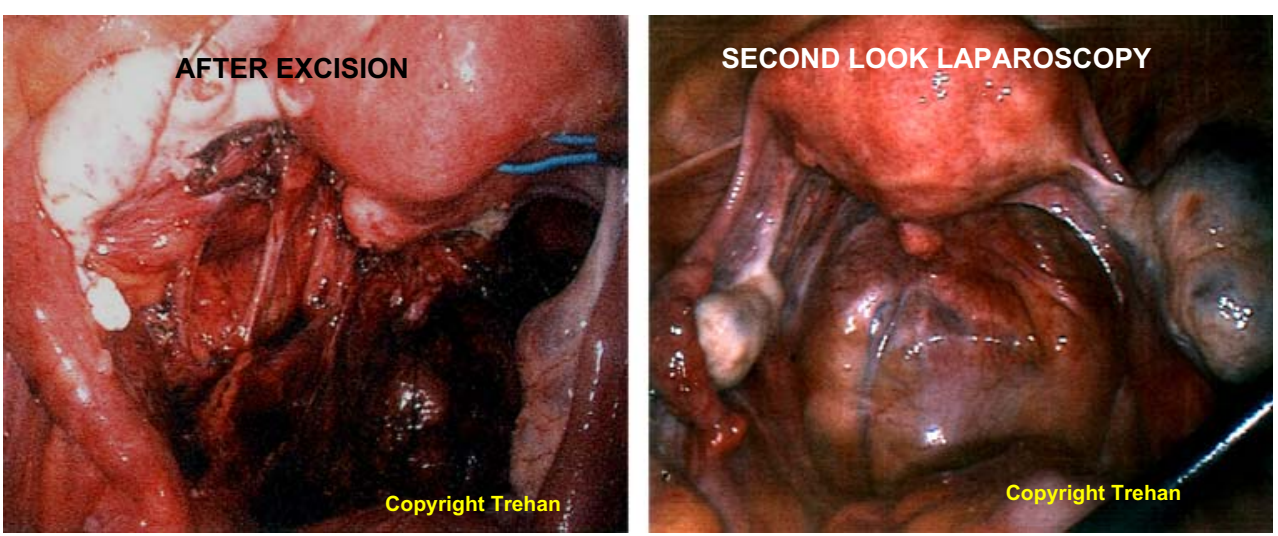

long-term consequences including fertility-related problems, chronic pelvic pain, and bowel obstruction [8]. The impact on the quality of life of these women is difficult to calculate. However, one could infer it from the increased number of claims against gynaecologists by these women. Between 1994 and 1999, the UK Medical Defence Union received 77 adhesion-related claims that resulted in 14 outof-court settlements in 11 years, averaging $£ 50,765$ per case [8]. Its impact on the healthcare system is also enormous. The estimated cost for the UK population, as extrapolated from the SCAR study in 1994, is about 67 million pounds [8].

In this paper, we set out to look specifically at the incidence of adhesion formation in patients who had total or partial laparoscopic excision of the pelvic peritoneum for pelvic endometriosis between 1988 and 2004. This paper to our knowledge is the first of its kind to look into the incidence of adhesion formation after total or partial peritoneal excision.

\section{Method}

This is a retrospective survey. It included all patients who had either a total or partial laparoscopic excision of pelvic peritoneum for pelvic endometriosis from April 1988 to March 2004 under the care of Mr Trehan at the Dewsbury District Hospital.

Table 1 Primary surgical procedures in 48 patients having secondlook operations

\begin{tabular}{ll}
\hline Operation & Number of patients \\
\hline $\begin{array}{l}\text { Laparoscopic excision of pelvic endometriosis } \\
\text { Other additional operation }\end{array}$ & 48 \\
Adhesiolysis & 13 \\
Ovarian cystectomy & 10 \\
LUNA & 7 \\
Ventrosuspension & 7 \\
Salpingectomy & 5 \\
Dye test & 5 \\
LAVH & 4 \\
Unilateral oophorectomy & 1 \\
\hline
\end{tabular}

We obtained data from the hospital computer database to identify all patients who had laparoscopic excision of pelvic peritoneum endometriosis during the study period.

\section{Operative technique}

All patients were admitted the day prior to surgery and had systemic bowel preparation. A three-port surgical procedure is performed, with a $10-\mathrm{mm}$ port at the umbilicus, and the side ports were $12 \mathrm{~mm}$ and $5 \mathrm{~mm}$. Scissors dissection of the pelvic peritoneum and endometriotic implants was performed. The use of diathermy was usually minimal. Intraabdominal pressure at operation was $12 \mathrm{mmHg}$ with saline and heparin irrigation $(5,000$ in of heparin in $1,000 \mathrm{ml}$ of saline). All patients had intravenous antibiotics (cefuroxime $750 \mathrm{mg}$ and metronidazole $500 \mathrm{mg}$ ) and adhesion prevention solution instilled (see Table 2) into the pelvic and abdominal cavity at the end of operation. The diagnosis was confirmed by histological examination of tissues removed at surgery. The majority of patients were discharged home the next day.

It is the usual practice in the unit and by the surgeon, $\mathrm{Mr}$ Trehan, to obtain photographs of the abdominal cavity and pelvis during laparoscopic operations in addition to written documentation in the patient's case records. See Fig. 1.

All subsequent admissions for abdominal surgery were reviewed for the presence of pelvic adhesions as documented in the case records and collaborated with photo-

Table 2 Post-operative use of adhesion prevention fluid (in 48 patients having second-look operations)

All patients received adhesion prevention solution

\begin{tabular}{ll}
\hline Type of fluid & Number of patients (\%) \\
\hline Sepracoat ${ }^{\circledR}$ & $21(43.75 \%)$ \\
Intergel $^{\circledR}$ & $18(37.5 \%)$ \\
Saline and heparin & $9(18.75 \%)$ \\
\hline
\end{tabular}

*Heparin dose 5000 iu in 1,000 ml normal saline 
Table 3 Surgical procedures at second-look operation (in 48 patients having second-look operations) some patients had one or more procedures

\begin{tabular}{ll}
\hline Surgical procedure & Number of patients \\
\hline Laparoscopic excision of endometriosis & 16 \\
LAVH only & 13 \\
Ophorectomy & 7 \\
Adhesiolysis & 4 \\
Ovarian cystectomy & 5 \\
TAH only & 4 \\
Dye test & 4 \\
LUNA & 3 \\
Excision of endometriotic nodule & 3 \\
Diagnostic laparoscopy & 2 \\
\hline
\end{tabular}

graphs from surgery. The presence of adhesion was deducted by comparing the pictures from the first laparoscopic surgery to the pictures at the second operation.

The classification of adhesions we used was the operative laparoscopic study group (OLSG) classification [13]. Adhesions were placed as: 0, none; 1, filmy and avascular; 2 , dense and vascular; and 3, binding and cohesive.

\section{Result}

Two hundred thirty-six patients were identified who had laparoscopic excision of pelvic peritoneum for pelvic endometriosis from April 1998 to March 2004. Forty-eight patients from the initial cohort returned to the unit for a second abdominal operation, either diagnostic or therapeutic.

The age range of patients was $20-42$ years, with an average age of 32.39 years. Twenty-four patients were nulliparous; 7 were para 1;12 were para 2; 7 were para 3 or more. The primary surgery for the cohort of patients who went on to have a second operation is shown in Table 1.
Table 5 Incidence of adhesion at 2nd look surgery by operative laparoscopy study group (OLSG) classification

\begin{tabular}{lll}
\hline OLSG Class & Description of adhesion & Number of patients (\%) \\
\hline 0 & None & $44(91.7 \%)$ \\
1 & $(8.3 \%)$ filmy/avascular* & 4 \\
2 & Dense/vascular & 0 \\
3 & Binding/cohesive & 0 \\
\hline
\end{tabular}

*Two patients received sepracoat, one patient intergel and one patient saline mixed with heparin at the end of excision surgery

At surgery, 25/48 (52.08\%) patients had stage 1, 14/48 (29.16\%) had stage 2, 5/48(10.42\%) had stage 3 and $4 / 48$ $(8.33 \%)$ had stage 4 endometriosis according to the revised American Fertility Society classification (rAFS).

All patients had post-operation adhesion prevention solution, albeit different brands (Table 2). In the study group, a majority $23 / 48(47.92 \%)$ of patients had no post-operative medical treatment; $22 / 48(45.83 \%)$ of patients had postoperative gonadotrophin-releasing hormone analogue treatment for 3 months, and 3/48 (6.25\%) had Danazol treatment for 3 months.

The surgical procedure at subsequent second-look surgery is shown in Table 3.

The time interval between first operation and subsequent surgery is shown in Table 4.

The presence and type of pelvic adhesions in the patients who had a subsequent abdominal surgical procedure according to the OLSG classification [13] is shown in Table 5.

\section{Discussion}

In our series, 44 patients $(91.7 \%)$ had no adhesions in the pelvis. Four patients had class 2 or filmy pelvic adhesions, that is, an incidence of $8.3 \%$. In the four patients with
Table 4 Time interval between first and second surgical operations

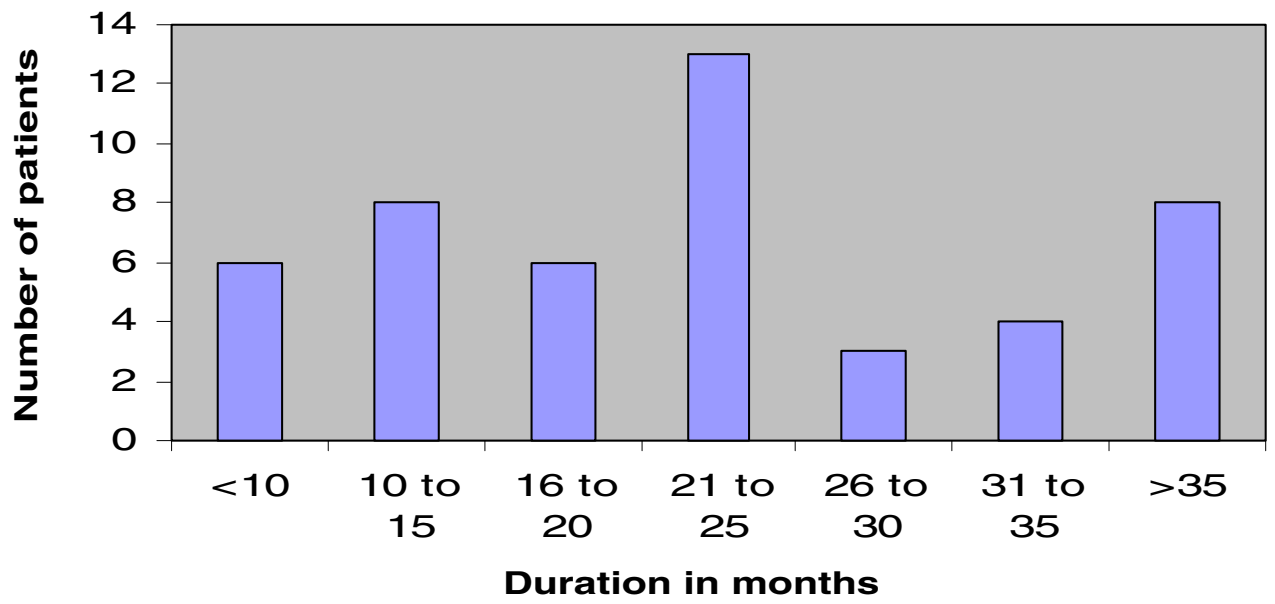


adhesions, one had rAFS* stage IV disease with a rectovaginal endometriotic nodule that was treated at second operation, one had rAFS stage III disease with an ovarian endometrioma and two had rAFS stage I disease had laparoscopic-assisted vaginal hysterectomy at primary surgery. We would deduce from our result that the presence of on-going endometriosis and additional major surgical procedure at the time of peritoneum excision increases the risk of adhesion formation.

The reasons for this good outcome, i.e., low incidence of adhesion could be due to a combination of the following factors.

\section{Operator experience \\ 2. Operator technique \\ 3. Use of adhesion prevention adjuvant.}

One surgeon, who had been trained in advanced laparoscopic surgery and practiced the same for over a decade, performed all operations. The role of good training in endoscopic surgery is not questionable. However there is currently an unresolved debate on the way forward in training-an apprenticeship model or modular training [14].

Adhesion formation starts after localised injury to the mesothelial layer of the peritoneum. The interaction between post-traumatic inflammatory proteins and fibrin deposits at the injury sites finally leads to adhesion formation [8]. Surgical technique is important to prevent adhesion formation after pelvic surgery [9]. Laparoscopic surgery is associated with less risk of adhesion formation as compared to laparotomy [12, 15-17]. Our surgical technique of laparoscopic excision with scissors dissection, minimal use of diathermy, gentle tissue handling, meticulous haemostasis and copious irrigation prevents charring of tissues due to thermal injury. This leads to a reduced stimulus for an inflammatory cascade reaction following tissue trauma and therefore less adhesion formation post surgery.

In our unit, all patients undergoing laparoscopic excision of endometriosis have intra-operative irrigation with saline mixed with heparin in addition to adhesion prevention solution at the end of surgery. The use of adhesion prevention solution has been extensively studied in the last decade. The general consensus from published data is that an adhesion prevention solution or barrier significantly reduces the incidence of post-operative adhesion formation [18-23]. The safety profile of the patients treated with adhesion prevention solution was comparable to those treated with lactated Ringer's solution [22, 23].

However several reports suggest that the use of gonadotrophin-releasing hormone angonist reduces pelvic adhesion after surgery [24-26]. The use of medical treatment after surgery is not routine in our unit and some patients decline to have this treatment after counselling because of the side effects. The effect on our result is limited because a majority of our patients did not have this treatment.

Our paper is the first to report on the incidence of adhesion formation after laparoscopic excision of the total or partial pelvic peritoneum with scissors dissection and post-operative use of adjuvant adhesion prevention solution. Our study suggests that laparoscopic excision of the pelvic peritoneum is a safe and effective treatment approach for women with pelvic peritoneum endometriosis. Also, if surgery is carried out in trained hands and with adherence to good surgical practice, it does not cause dense adhesion in the pelvis.

We accept there are limitations to this paper. It is a retrospective study, with a small sample population. However, it offers a snapshot on laparoscopic excision of pelvic peritoneum and pelvic adhesion formation.

\section{References}

1. Garry R, Clayton R, Hawe J (2000) The effect of endometriosis and its radical laparoscopic excision on quality of life indicators. BJOG 107(1):44-54, Jan

2. Abbott J, Hawe J, Hunter D, Holmes M, Finn P (2004) Garry laparoscopic excision of endometriosis: a randomized, placebocontrolled trial. Fertil Steril 82(4):878-884, Oct

3. Jacobson TZ, Barlow DH, Garry R, Koninckx P (2001) Laparoscopic surgery for pelvic pain associated with endometriosis. Cochrane Database Syst Rev 2(4):CD001300

4. Jacobson TZ, Barlow DH, Koninckx PR, Olive D, Farquhar C (2002) Laparoscopic surgery for subfertility associated with endometriosis. Cochrane Database Syst Rev 2(4):CD001398

5. Keye WR Jr, Hansen LW, Astin M, Poulson AM Jr (1987) Argon laser therapy of endometriosis: a review of 92 consecutive patients. Fertil Steril 47(2):208-212, Feb

6. Sutton CJ, Ewen SP, Whitelaw N, Haines P (1994) Prospective, randomized, double-blind, controlled trial of laser laparoscopy in the treatment of pelvic pain associated with minimal, mild, and moderate endometriosis. Fertil Steril 62(4):696-700, Oct

7. Sutton CJ, Pooley AS, Ewen SP, Haines P (1997) Follow-up report on a randomized controlled trial of laser laparoscopy in the treatment of pelvic pain associated with minimal to moderate endometriosis. Fertil Steril 68(6):1070-1074, Dec

8. Trew G (2004) Consensus in adhesion reduction management. Obstetr Gynaecol Suppl 6(2):1

9. Monk BJ, Berman ML, Montz FJ (1994) Adhesions after extensive gynecologic surgery: clinical significance, etiology, and prevention. Am J Obstet Gynecol 170(5 Pt 1):1396-1403, May

10. Menzies D, Ellis H (1990) Intestinal obstruction from adhesionshow big is the problem? Ann R Coll Surg Engl 72(1):60-63, Jan

11. Ellis H, Moran BJ, Thompson JN, Parker MC, Wilson MS, Menzies D, McGuire A, Lower AM, Hawthorn RJ, O'Brien F, Buchan S, Crowe AM (1999) Adhesion-related hospital readmissions after abdominal and pelvic surgery: a retrospective cohort study. Lancet 353(9163):1476-1480, May 1

12. Lower AM, Hawthorn RJ, Clark D, Boyd JH, Finlayson AR, Knight AD, Crowe AM, Surgical and Clinical Research (SCAR) 
Group (2004) Adhesion-related readmissions following gynaecological laparoscopy or laparotomy in Scotland: an epidemiological study of 24,046 patients. Hum Reprod 19(8):1877-1885, Aug. Epub (2004), Jun 3

13. Chapron C, Guibert J, Fauconnier A, Viera M, Dubuisson JB (2001) Adhesion formation after laparoscopic resection of uterosacral ligaments in women with endometriosis. J Am Assoc Gynecol Laparosc 8(3):368-373, August

14. Wright $J$ (2005) Training in minimal access gynaecological surgery. Gynecol Surg 2:1-2

15. Lundorff P, Hahlin M, Kallfelt B, Thorburn J, Lindblom B (1991) Adhesion formation after laparoscopic surgery in tubal pregnancy: a randomized trial versus laparotomy. Fertil Steril 55(5):911-915, May

16. Takeuchi H, Kinoshita K (2002) Evaluation of adhesion formation after laparoscopic myomectomy by systematic second-look microlaparoscopy. Am Assoc Gynecol Laparosc 9(4):442-446, Nov

17. Gutt CN, Oniu T, Schemmer P, Mehrabi A, Buchler MW (2004) Fewer adhesions induced by laparoscopic surgery? Surg Endosc 18(6):898-906, Jun, Epub (2004), Apr 27

18. Farquhar C, Vandekerckhove P, Watson A, Vail A, Wiseman D (2000) Barrier agents for preventing adhesions after surgery for subfertility. Cochrane Database Syst Rev (2):CD000475

19. Azziz R (1993) Microsurgery alone or with INTERCEED Absorbable Adhesion Barrier for pelvic sidewall adhesion reformation. The INTERCEED (TC7) Adhesion Barrier Study Group II. Surg Gynecol Obstet 177(2):135-139, Aug

20. diZerega GS (1996) Use of adhesion prevention barriers in ovarian surgery, tubalplasty, ectopic pregnancy, endometriosis, adhesiolysis, and myomectomy. Curr Opin Obstet Gynecol 8 (3):230-237, Jun
21. Diamond MP (1998) Reduction of de novo postsurgical adhesions by intraoperative precoating with Sepracoat (HAL-C) solution: a prospective, randomized, blinded, placebo-controlled multicenter study. The Sepracoat Adhesion Study Group. Fertil Steril 69 (6):1067-1074, Jun

22. Johns DB, Keyport GM, Hoehler F, diZerega GS, Intergel Adhesion Prevention Study Group (2001) Reduction of postsurgical adhesions with Intergel adhesion prevention solution: a multicenter study of safety and efficacy after conservative gynecologic surgery. Fertil Steril 76(3):595-604, Sep

23. diZerega GS, Verco SJ, Young P, Kettel M, Kobak W, Martin D, Sanfilippo J, Peers EM, Scrimgeour A, Brown CB (2002) A randomized, controlled pilot study of the safety and efficacy of $4 \%$ icodextrin solution in the reduction of adhesions following laparoscopic gynaecological surgery. Hum Reprod 17(4):10311038, Apr

24. Schindler AE (2004) Gonadotropin-releasing hormone agonists for prevention of postoperative adhesions: an overview. Gynecol Endocrinol 19(1):51-55, Jul

25. Wright JA, Sharpe-Timms KL (1995) Gonadotropin-releasing hormone agonist therapy reduces postoperative adhesion formation and reformation after adhesiolysis in rat models for adhesion formation and endometriosis. Fertil Steril 63(5):1094 1100, May

26. Sharpe-Timms KL, Zimmer RL, Jolliff WJ, Wright JA, Nothnick WB, Curry TE (1998) Gonadotropin-releasing hormone agonist $(\mathrm{GnRH}-\mathrm{a})$ therapy alters activity of plasminogen activators, matrix metalloproteinases, and their inhibitors in rat models for adhesion formation and endometriosis: potential GnRH-a-regulated mechanisms reducing adhesion formation. Fertil Steril 69(5): 916-923, May 